\title{
SIMULATING THE EFFECT OF NON-DARCY FLOW AND HYDRAULIC FRACTURING ON WELL PRODUCTIVITY IN A NATURALLY FRACTURED LEAN GAS CONDENSATE RESERVOIR
}

\author{
a Momeni, A. ${ }^{\text {; }}{ }^{\text {b }}$ Zargar, G.; ${ }^{\text {b Sabzi, A. A. }}$ \\ a Department of Petroleum Engineering, Science and Research branch, Islamic Azad University, Tehran, Iran \\ ${ }^{b}$ Department of Petroleum Engineering, Petroleum University of Technology, Tehran, Iran
}

\begin{abstract}
Condensate formation near the wellbore area of gas condensate reservoirs, below the fluid dew point, reduces the gas relative permeability and, consequently, decreases the well productivity. Alternative solutions including drilling horizontal wells, hydraulic fracturing in vertical wells, gas recycling, and increasing production rate can prevent the reduction of productivity. Hydraulic fracturing has been introduced as one of the frequently-used methods to enhance the productivity in gas wells. The main goal of this study is to numerically simulate the effect of hydraulic fracturing and non-Darcy flow on well productivity of an Iranian gas condensate naturally fractured reservoir by the CMG-GEM, which is a commercial simulator. The studied reservoir is of 'lean gas condensate' type at which the condensed volume is at most $1 \%$ of the total volume. The studied reservoir was modelled in two approaches. In the first model, the reservoir includes a network of natural fractures modelled by dual porosity approach; while, in the second model, single porosity method was used to model the reservoir. Both models were run in the existence of hydraulic fractures and without them. The outputs showed that hydraulic fractures did not affect the productivity index in the dual porosity model; however, such fractures increased the productivity index of the single porosity model. In the next step, non-Darcy flow conditions were added to the previous runs. Presence of the non-Darcy flow decreased the productivity index where the productivity reduction was substantial in the dual porosity model.
\end{abstract}

\section{KEYWORDS}

gas condensate; hydraulic fracture; non-Darcy flow; productivity index

\footnotetext{
${ }^{1}$ To whom all correspondence should be addressed.

Address: Department of Petroleum Engineering, Science and Research branch, Islamic Azad University, Tehran, Iran e-mail: ahmad.momeni@srbiau.ac.ir

doi:10.5419/bjpg2011-0018
} 


\section{INTRODUCTION}

Gas condensate reservoirs have been classified between volatile oil and wet gas reservoirs. In other words, the reservoir temperature is between the critical temperature and the cricondentherm (Wang et al., 2000).

Gas condensate reservoirs behave similarly to single phase gas reservoirs in the early production period. Afterwards, as recovery increases and reservoir pressure decreases, heavy components separate from the gas phase and form a precious accumulation of intermediate condensates (C2-C7) around the wellbore. This phenomenon plugs the pores on the wellbore or makes a condensate bank as a result of a combination of different parameters including fluid phase behavior, flow conditions in the reservoir, reservoir pressure, and wellbore pressure. Condensate formation, near the wellbore area, causes two major problems. A relatively large volume of valuable condensates will remain in the reservoir and will not be produced. Also, the condensate bank reduces relative permeability to gas. It tightens gas flow and blocks the connected pore throats of the reservoir rock. Condensate deposition eventually will weaken the well productivity (Williams and Dawe, 1989).

Afidick et al. (1994) studied the Arun reservoir in Indonesia, which is one of the world largest gas condensate reservoirs. They found that the productivity considerably decreased after 10 years of production because of condensate deposition near the wellbores. Their studies showed that the productivity index of a well decreased 2 to 4 folds as the condensates deposited. They also concluded that even for light gases with a small amount of condensate, there was a possibility of formation of high condensate saturation near the wellbore region and, consequently, productivity reduction.

Chen et al. (1999) studied the fluids phase behavior of two gas condensate reservoirs in the North Sea, and concluded that the critical condensate saturation and relative permeability data are sensitive to the production rate. In a gas condensate reservoir, gas velocities near the well are generally very high, and Darcy's law may not be valid if the Reynold's number exceeds values on the order of 1.0.

Sognesand (1991) investigated the effect of fluids flow prevention near wellbore blocks, including natural vertical fractures by condensate deposition. He found that the amount of condensate accumulation close to the vertical fractures around the gas condensate wells depends on the relative permeabilities and production scenario. He stated that the gas relative permeability increases whenever the condensate accumulation is reduced. Sognesand (1991) reported that the highest pressure drop close the condensate bank occurs around the natural fractures.

Ahmed et al. (2002) studied the effect of pressure drop on production of the Ghawar gas condensate field by estimating the amount of deposited condensate in presence and absence of hydraulic fractures. They also investigated the effect of non-Darcy flow. They concluded that after hydraulic fracturing and reducing the deposited condensate, the gas (a rich gas with $35 \%$ of condensate volume) production increased up to $80 \%$. Ahmed et al. (2002) reported the productivity reduction in hydraulically fractured wells is smaller than that in non-fractured wells due to the smaller saturation of condensate in presence of hydraulic fractures. Finally, they concluded that hydraulic fractures reduce the effect of non-Darcy flow in gas condensate wells.

The main objective of this study is to investigate the effect of hydraulic fractures and non-Darcy flow on productivity of well 11 of field $A$ (an Iranian gas condensate field) by numerical simulation. The reservoir's pressure has not fallen below the dew point and condensate banks have not been formed yet.

\section{MATERIALS AND METHODS}

\subsection{Fluid phase behavior}

Produced gas of field A contains condensate of about 16-18STB/MMSCF. The phase behavior of the fluid sample of the studied well was modelled using a PVT simulator. The output of the PVT model was imported to the reservoir simulator after obtaining a suitable match between estimated values and measured lab data. Table 1 shows the fluid composition. 
Table 1. Fluid composition (mole \%).

\begin{tabular}{c|cccccccccccccccc}
\hline Component & $\mathrm{N} 2$ & $\mathrm{CO} 2$ & $\mathrm{H} 2 \mathrm{~S}$ & $\mathrm{C} 1$ & $\mathrm{C} 2$ & $\mathrm{C} 3$ & $\mathrm{iC} 4$ & $\mathrm{nC} 4$ & $\mathrm{iC} 5$ & $\mathrm{nC} 5$ & $\mathrm{C} 6$ & $\mathrm{C} 7$ & $\mathrm{C} 8$ & $\mathrm{C} 9$ & $\mathrm{C} 10$ & $\mathrm{C} 11$ \\
\hline Mole \% & 2.26 & 1.32 & 0 & 86.96 & 4.95 & 1.55 & 0.39 & 0.51 & 0.26 & 0.21 & 0.33 & 0.37 & 0.33 & 0.2 & 0.13 & 0.08 \\
\hline
\end{tabular}

\subsection{Reservoir modeling}

A synthetic model was constructed for the studied case. This work focused on studying the well 11 and the flow behavior close to the wellbore; therefore the grid sizes were chosen fine in that region, and rest of the reservoir was not studied.

The simulation was done using a compositional simulator. The reservoir model was built in 3 dimensions: length $(\mathrm{X})$, width $(\mathrm{Y})$, and height $(\mathrm{Z})$. The size of the modeled reservoir was $X=2030 \mathrm{ft}, Y=$ $2030 \mathrm{ft}$, and $Z=1320 \mathrm{ft}$. Reservoir gridding was in $X$ and $Y$ direction using a single well model (a production well at the center of the reservoir). Figure 1 illustrates the reservoir gridding model.

The size of the grids was chosen from a small area near the wellbore region. The block width was $0.9 \mathrm{ft}$ in that region. Also, size of the middle block in $Y$ direction was reduced to $0.1 \mathrm{ft}$ by local grid refining (LGR). In other words, hydraulic fracture width was fixed at $0.1 \mathrm{ft}$.

The reservoir included 12 layers in $Z$ direction, being 6 layers in the 'Kangan' reservoir and the rest of the layers in 'Upper Dalan'. Porosities of the layers varied from $2 \%$ to $13 \%$. Permeability in $Y$ direction was the same as permeability in $X$ direction, and ranged from $0.12 \mathrm{mD}$ to $1 \mathrm{mD}$. Permeability in $\mathrm{Z}$ direction was $50 \%$ of that in $\mathrm{X}$

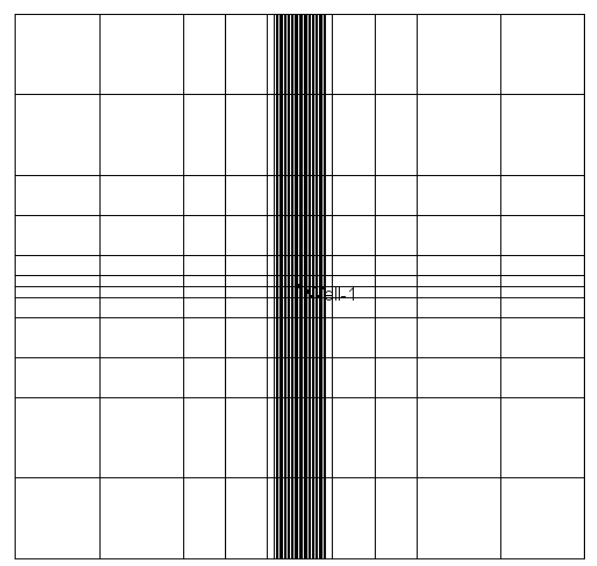

Figure 1. The reservoir gridding model. direction. Also, hydraulic fracture permeability was $300 \mathrm{mD}$. Due to lack of the measured data, natural fractures porosity, according to Nelson's theory (Nelson, 2001), was supposed $1 \%$ of the reservoir bulk volume. Nelson's theory states that natural fractures porosity is always less than $2 \%$ of the total reservoir volume and it is less than $1 \%$ in most of the reservoirs.

The well had been drilled in all layers, and it is assumed that all the layers were open to production. Initial reservoir pressure was about 3380 psi, which was close to the dew point of about 3330psi. Furthermore, the reservoir temperature was at $197^{\circ} \mathrm{F}$ at the datum depth of $2926 \mathrm{~m}$. The gas production rate was constant and about 5,000,000 SCFD and 1,000,000 SCFD, respectively, in single porosity and dual porosity models.

\section{RESULTS AND DISCUSSION}

\subsection{Relative permeability model}

Water and gas relative permeabilities were measured in the lab. The measured data showed that the average water saturation was about $33 \%$. A general relative permeability curve was built for all layers according to the average water saturation. Water and oil relative permeability in the rock matrix are illustrated in Figure 2.

Gas and condensate relative permeabilities were estimated using Corey equations (Corey, 1954). Equations (1) and (2) are the Corey equations. $K_{r o}$ is the condensate relative permeability in equation (2).

$$
\begin{aligned}
& k_{r g}=k_{r g_{\max }}\left(\frac{S_{g}-S_{g c}}{1-S_{w}-S_{g_{c}}-S_{c c}}\right)^{m} \\
& k_{r o}=k_{r o_{\max }}\left(\frac{1-S_{w}-S_{c c}-S_{g}}{1-S_{w}-S_{c c}-S_{g c}}\right)^{n}
\end{aligned}
$$




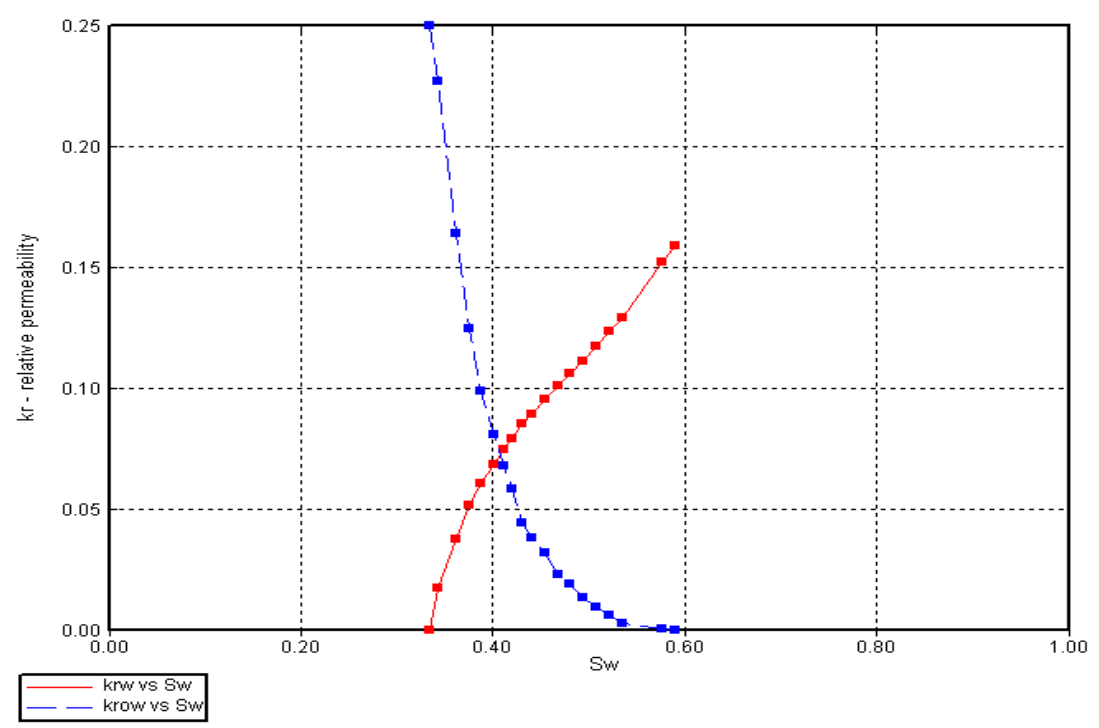

Figure 2. Water-Oil relative permeability in the rock matrix.

In these relations $\mathrm{S}_{\mathrm{gc}}=0.001, \mathrm{~S}_{\mathrm{cc}}=0.05, \mathrm{~S}_{\mathrm{w}}=0.33$, $m=2$, and $n=2$.

Figure 3 shows the gas/condensate relative permeability curve which was generated by Corey equations. For the natural fractures, a linear profile between 0 and 1 was applied for relative permeability of water/gas and gas/condensate systems.

\subsection{Non-Darcy flow}

Forcheimer (1901) emphasized that his laboratory results of flowing water in a porous media, at high velocities, were not consistent with the Darcy law. He suggested a modification of
Darcy law to account for high velocity condition, as follows.

$$
-\frac{d P}{d r}=\frac{\mu}{k} v+\beta \rho v^{2}
$$

where $\rho$ is the flow density and $\beta$ is the non-Darcy flow coefficient, which depends on the porous media properties. At very low Reynolds numbers, $v$ tends to zero, and the second term at the righthand side of equation (3) cancels out; so the equation changes to Darcy equation. Ahmed and McKinney (2005) integrated non-Darcy skin into other skins in mathematical formulas of different flow regimes.

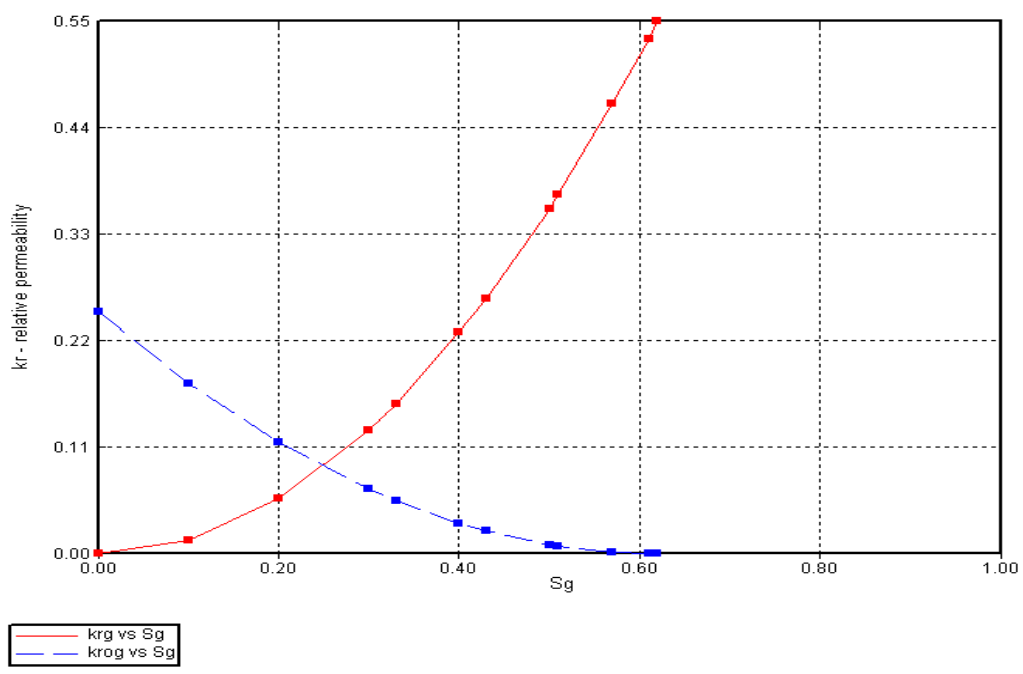

Figure 3. Gas condensate relative permeability in the rock matrix. 


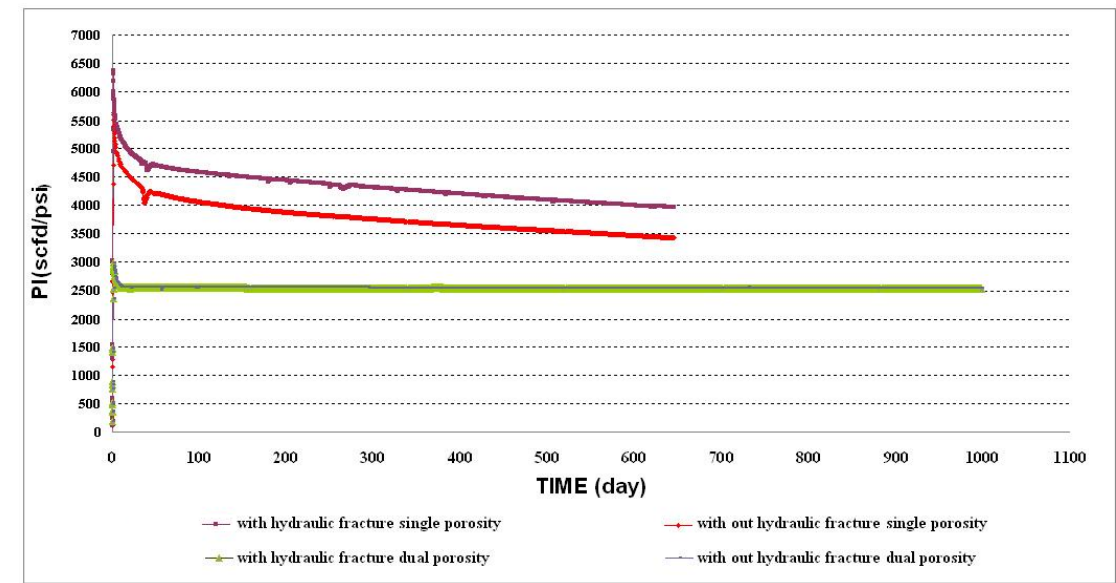

Figure 4. The effect of hydraulic fracturing on productivity index of single and dual porosity models.

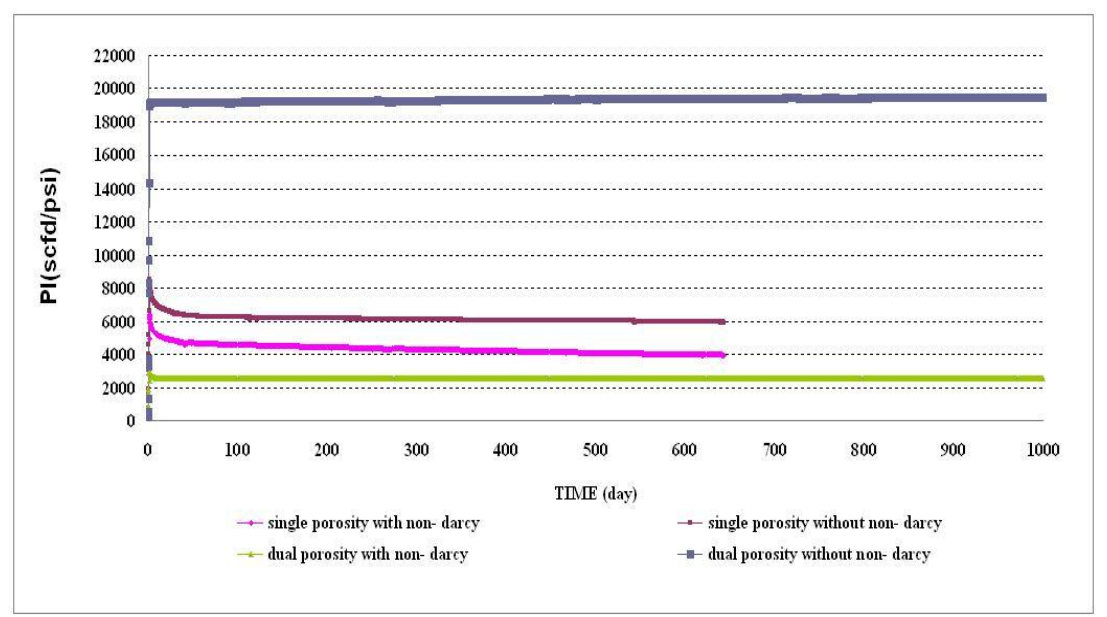

Figure 5. The non-Darcy flow effect on productivity index of single and dual porosity models.

Geertsma (1974) developed a new correlation for $\beta$, which is applied in multiphase flow conditions (equation (4)). He used laboratory data and dimensional analysis to correlate non-Darcy flow coefficient $(\beta)$, permeability $\left(\mathrm{kk}_{\mathrm{rg}}\right)$, and porosity $(\Phi)$.

$\beta=\frac{0.005}{\left(k k_{r g}\right)^{0.5}\left(\Phi\left(1-s_{w}\right)\right)^{5.5}}$

\subsection{Numerical simulation}

First, a hydraulic fracture was applied in three bottom layers of the reservoir and at the bottom of the well, in both models. Effective fracture halflength of $115 \mathrm{ft}$, width of $0.1 \mathrm{ft}$, and permeability of
$300 \mathrm{mD}$ for single porosity model; and $1500 \mathrm{mD}$ for dual porosity model, were considered for hydraulic fractures in the simulation runs. Geertsma's (1974) model was used to estimate the effect of nonDarcy flow. Then, the productivity of the well was compared to that of a non-fractured model. As it is shown in Figure 4, the hydraulic fracture causes a $15 \%$ increment in the productivity index of the single porosity model; however, for dual porosity model only a minor increment of about $0.01 \%$ was obtained.

Applying the non-Darcy flow effect to both models, results show that the productivity index during non-Darcy flow was $657 \%$ less than that, disregarding the non-Darcy flow after 1000 days of production in dual porosity model. While the productivity index during non-Darcy flow was $37 \%$ 


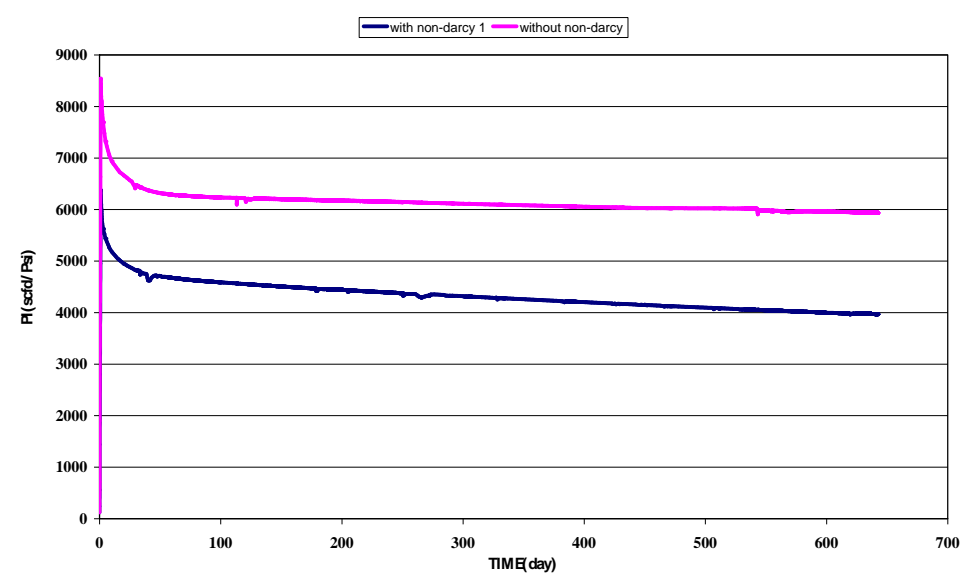

Figure 6. The non-Darcy flow effect in the single porosity model in presence of the hydraulic fracture.

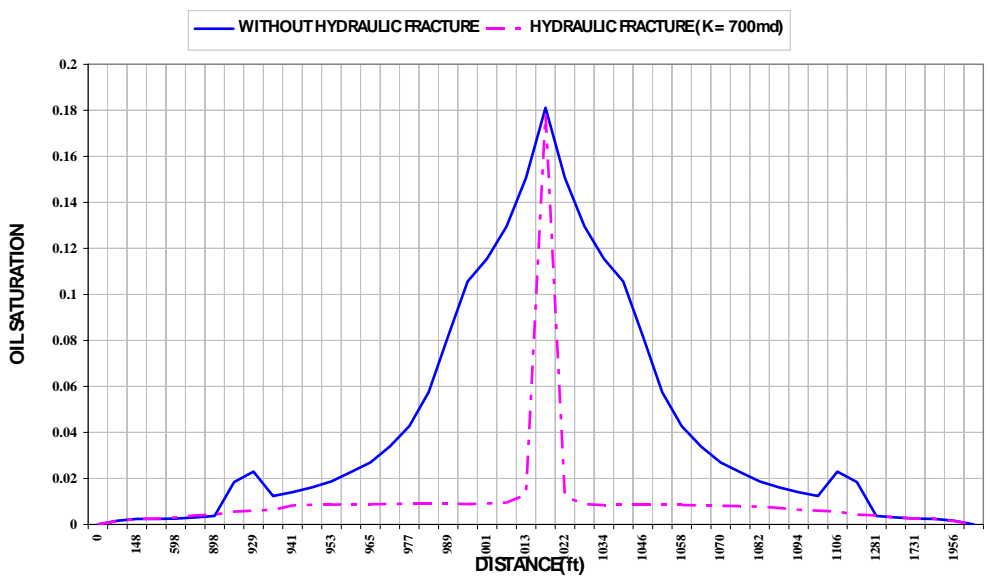

Figure 7. The condensate bank near wellbore region after 730 days of production, in the 12th layer of the single porosity model.

less than that, if non-Darcy flow was ignored during the production after 630 days on the single porosity model. The impact of non-Darcy flow was estimated using the Geertsma's (1974) model. Figure 5 shows the productivity index results for dual and single porosity models with and without non-Darcy flow conditions.

Figure 6 shows the effect of non-Darcy flow, Geertsma (1974) model, on productivity index of single porosity model after applying hydraulic fracture. Productivity index was decreased $43 \%$ during 640 days of production.

The radius of condensate region in the single porosity models prior to and after applying hydraulic fracture was illustrated in Figure 7. Although hydraulic fracture increases the undesirable effect of non-Darcy flow; it reduces the radius of condensate region. Therefore productivity index increases, eventually.

Single and dual porosity models in presence of non-Darcy flow and without hydraulic fractures were compared as it was shown in Figure 8. The results showed that the productivity index of the dual porosity model is less than that of the single porosity model. For instance, the differences between productivity indexes are $63 \%$ and $22 \%$, after 70 and 1000 days of production, respectively. This can be explained by natural fracture networks. The velocity of fluids is higher because of the higher permeability in the fractures and, therefore, the increase in pressure loss when non-Darcy effect is included in the model. 


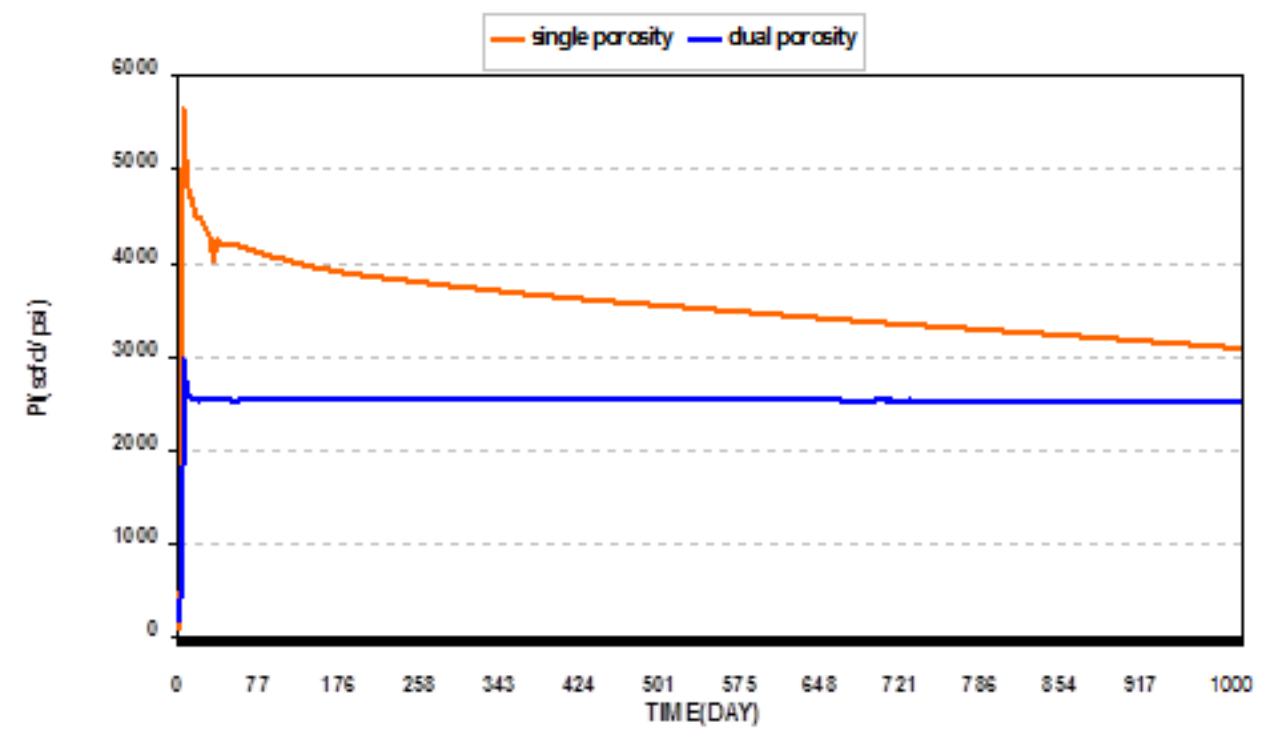

Figure 8. Comparison of the single and dual porosity models under the same conditions and without hydraulic fractures.

\section{CONCLUSIONS}

This study led to the following conclusions:

(1) The non-Darcy flow effect must be considered in productivity estimation of gas condensate wells with hydraulic fractures because the fluid velocity is high close to the hydraulic fractures.

(2) Most of the previous studies concentrated on increasing the productivity index of rich gas condensate wells (ones with more than $5 \%$ condensation). This study demonstrated that hydraulic fracturing can increase the productivity index of a specific lean gas condensate (ones with less than $1 \%$ condensation) well in the single porosity model.

(3) Hydraulic fracture reduces the radius of the condensate region in the direction of the hydraulic fracture in the single porosity model.

(4) The productivity index of the dual porosity model in presence of the non-Darcy flow is smaller than that of the single porosity model.

\section{NOMENCLATURE}

g Gas

k Absolute permeability

$\mathrm{k}_{\mathrm{r}} \quad$ Relative permeability

o Oil

P Pressure

S Saturation

w Water

X $\quad x$ direction

Y y direction

Z $\quad$ direction

$\beta \quad$ non-Darcy flow coefficient

$\rho \quad$ Density

$\mu \quad$ Viscosity

$\Phi \quad$ Porosity

\footnotetext{
1 feet $(\mathrm{ft})=0.3084$ meters $(\mathrm{m})$

1 pounds- force/sq .inch $(\mathrm{Psi})=6894.757 \mathrm{Pascal}(\mathrm{Pa})$

100 Fahrenheit $\left({ }^{\circ} \mathrm{F}\right)=37.77$ Celsius $\left({ }^{\circ} \mathrm{C}\right)$
} 


\section{REFERENCES}

Afidick, D.; Kaczorowski, N.J.; and Bette, S. Production Performance of Retrograde Gas Reservoir: A Case Study of the Arun Field, SPE 28749, paper presented at the SPE Asia Pacific Oil and Gas Conference, Melbourne, Australia, November 7-10, 1994. http://dx.doi.org/10.2118/28749-MS

Ahmed, M.; Evans, J.; Kwan, R.; Vivian, T. Quantifying Production impairment Due To NearWellbore Condensate Dropout and Non-Darcy Flow Effects in Carbonate and Sandstone Reservoirs With and Without Hydraulic Fractures in the Ghawar Field, Saudi Arabia, SPE 77552, paper presented at the SPE Annual Technical Conference and Exhibition, San Antonio, TX, September 29October 2, 2002. http://dx.doi.org/10.2118/77552-MS

Ahmed, T.; McKinney, P. D. Advanced Reservoir Engineering. Houston: Gulf Publishing Company, p. 53-54, 2005.

Chen, H. L.; Wilson, S. D.; Monger-McClure, T.G. Determination of Relative Permeability and Recovery for North Sea Gas Condensate Reservoir, SPEREE, August, p. 393-402, 1999.

Corey, A. T. The interrelation between gas and oil relative permeabilities. Prod. Monthly, 19, No. 1, 38-41, 1954.
Forcheimer ,P. Wasserbewegung durch Boden, Zeitz.Ver.deutsch Ing., Berlin 45, 1781-1788, 1901, (in German).

Geertsma, J. Estimating the Coefficient of Inertial Resistance in Fluid Flow through Porous Media, SPEJ, October, p. 445-450, 1974.

Nelson, R.A. Geologic Analysis of Naturally Fractured Reservoirs. Boston: Gulf Professional Publishing, 2001.

Sognesand, S. Long Term Testing of Vertically Fractured Gas Condensate Wells, SPE 21704, paper presented at SPE Production Operations Symposium, Oklahoma City, Oklahoma, April 7-9, 1991. http://dx.doi.org/10.2118/21704-MS

Wang, X.; Indriati, S.; Valko, P.P.; Economides, M.J. Production Impairment and Purpose-Built Design of Hydraulic Fractures in Gas- Condensate Reservoirs, SPE 64749S, paper presented at International Oil and Gas Conference and Exhibition, Beijing, China, 7-10 November 2000. http://dx.doi.org/10.2118/64749-MS

Williams, J.K., Dawe, R.A., Imperial C. NearCritical Condensate Fluid Behavior in Porous Media-A Modeling Approach, SPE Reservoir Engineering, May, p. 221-227, 1989. http://dx.doi.org/10.2118/17137-PA 